This item was submitted to Loughborough's Research Repository by the author.

Items in Figshare are protected by copyright, with all rights reserved, unless otherwise indicated.

\title{
An evaluation of nonprofit brand image: towards a better conceptualization and measurement
}

\section{PLEASE CITE THE PUBLISHED VERSION}

http://dx.doi.org/10.1016/j.jbusres.2015.03.024

\section{PUBLISHER}

(C) Elsevier

\section{VERSION}

AM (Accepted Manuscript)

\section{PUBLISHER STATEMENT}

This work is made available according to the conditions of the Creative Commons Attribution-NonCommercialNoDerivatives 4.0 International (CC BY-NC-ND 4.0) licence. Full details of this licence are available at: https://creativecommons.org/licenses/by-nc-nd/4.0/

\section{LICENCE}

CC BY-NC-ND 4.0

\section{REPOSITORY RECORD}

Michaelidou, Nina, M Micevski, and John Cadogan. 2015. "An Evaluation of Nonprofit Brand Image: Towards a Better Conceptualization and Measurement”. Loughborough University. https://hdl.handle.net/2134/17156. 
An Evaluation of Nonprofit Brand Image: Towards a Better Conceptualization and Measurement

\author{
Nina Michaelidou* \\ School of Business and Economics, Loughborough University \\ Leicestershire, LE11 3TU, UK \\ Email: N.Michaelidou@lboro.ac.uk \\ Tel: +44 (0)1509 222435 \\ Milena Micevski \\ School of Business and Economics, Loughborough University \\ Leicestershire, LE11 3TU, UK \\ Email: M.Micevski@lboro.ac.uk
}

Tel: +44 (0)1509 223177

John W. Cadogan

School of Business and Economics, Loughborough University

Leicestershire, LE11 3TU, UK

Email: J.W.Cadogan@lboro.ac.uk

Tel: +44 (0)1509 228846 


\begin{abstract}
Nonprofit brand image plays an important role in shaping consumers' charitable donations and therefore nonprofit organizations must be aware of how consumers perceive them. This research examines nonprofit brand image and reports findings from three empirical studies, which aim to offer a better conceptualization and measurement of the concept. Study 1 investigates the psychometric properties of the Michel and Rieunier's (2012) nonprofit brand image scales with a sample from the UK, and reports key methodological limitations. Specifically, discriminant and convergent validity tests highlight the need for further research into the dimensionality of the nonprofit brand image measures. Subsequently, studies 2 and 3 offer an improved conceptualization and measurement of nonprofit brand image and validate the scales via the use of 2 separate data sets. The new measures consists of 6 dimensions namely, usefulness, efficiency, affect, dynamism, reliability and ethicality which are significantly related to intentions to donate money and time.
\end{abstract}

Keywords: Nonprofit Brand Image, Scale Evaluation, Scale Validation, Scale Extension and Improvement 


\section{INTRODUCTION}

\subsection{Brand Image}

Brand image is at the heart of an organization's promotional activities (Bendapudi et al., 1996) since it has the ability to shape consumers' attitudes toward the brand, product and service, and to influence their actions, including behavior toward the organization (e.g. Park et al., 1990; Cheung and Chan 2000; Romaniuk and Nenycz-Thiel 2013). Notwithstanding, less agreement exists with regard to brand image conceptualization and measurement (Keller, 1993). Research views brand image as: a collection of ideas, feelings and attitudes that consumers have about brands (Gardner and Levy, 1955; Schmitt, 2012); a mental representation of meaning (Paivio, 1969); a concept that sums up the ideas that consumers buy into brands for the meanings connected to them beyond their physical attributes (Levy and Glick, 1973).

According to Keller (1993), brand image encompasses consumers’ perceptions about a brand, which form from brand associations in the memory, and is defined as "perceptions about a brand reflected by the brand associations held in consumer memory” (p. 3). Brand image, while related to the concepts of reputation and corporate identity is conceptualized and measured differently. In particular, reputation refers to a concept with a historical connotation, which evolves over time and which denotes a value judgment about an organization's qualities (Balmer, 1998). Similarly, image differs from identity since identity is used to refer to an organization's character or personality, which reflects the organization's ideology and values and which affects organizational practices (Balmer, 1995; Bennett and Gabriel, 2003). In contrast, image captures consumers' mental representations of an organization, and transcends beyond reputation and identity (Keller, 1993; Bennett and Gabriel, 2003; Schmitt, 2012). In this sense, consumers may 
develop brand associations encompassing, but not limited to, aspects of identity and reputation, and which can fashion quickly (Bennett and Sargeant, 2005).

\subsection{Brand Image in the Nonprofit Context}

Government and corporate reductions in charity funding and the public's lesser disposable income cause charities and other nonprofit organizations to struggle to source voluntary income (BBC, 2013). However, a report by the Charity Aid Foundation (2013) provides an optimistic picture in terms of charitable giving growth, predicting a potential rise in worldwide charitable giving of approximately \$233bn by 2030. This is quite optimistic given that charity income most frequently comes from the general public (23\%), investments (21\%) and membership fees (17\%) (Charity Commission, 2013). However, to attract donations charities face severe competition for potential donors' time, effort, and money and as a result they attempt to identify new ways to differentiate from competitors; placing emphasis on branding techniques represents one such way (Stride and Lee, 2007; Mort et al., 2007).

Within the nonprofit sector, the brand is a facet of charities that plays an important role (Chapleo, 2013). Understanding the role of branding and how consumers perceive charities is critical if charities are to shape consumer behavior to their advantage for example, through consumer advocacy. According to Keller (1998) positive brand image directly impacts brand equity and consumer behavior, and this transcends to the nonprofit context (Stride and Lee, 2007). Nevertheless, while there has been considerable research on branding in the nonprofit context (e.g. Saxton, 1995; Henley, 2001; Hankinson, 2001; Hudson, 2008; Stride and Lee, 2007; Mort et al., 2007; Pope et al., 2009; Waters and Jones, 2011; Chapleo, 2013; Juntunen et 
al., 2013), Stride and Lee (2007) suggest that branding is still “ an emergent concept in the charity context” (p. 113). Indeed, this is true to this date as less research focuses on the construct of brand image, its conceptualization and measurement within the nonprofit context (Michel and Rieunier, 2012). Toward this goal, Michel and Rieunier (2012) put forward a conceptualization of nonprofit brand image which consists of four dimensions. According to Michel and Rieunier (2012), consumers perceive nonprofit brands as useful, efficient, affective, and dynamic. The authors subsequently develop scales of nonprofit brand image within a specific charity context, and call for their validation in other countries and in different nonprofit organizations.

Given the apparent importance of brand image in a nonprofit context in affecting brand equity and consumer behavior, the scarcity of suitable nonprofit brand image measures, and lastly in responding to Michell and Rieunier’s (2012) call for validation of their scales, the current research aims to present an improved theoretical understanding and measure of nonprofit brand image and its dimensions. The authors conduct three empirical studies which first investigate the psychometric properties of the Michel and Rieunier's (2012) nonprofit brand image scales (Study 1) and subsequently conceptually improve and validate the scales (Studies 2 \& 3), due to apparent measurement limitations evidenced in Study 1. The research offers both theoretical and methodological contributions as it presents an improved conceptualization and a better measurement of nonprofit brand image, relative to the original of Michel and Rieunier (2012), with scales that have higher explanatory power than the originals and with evidence of generalizability. The following section reviews the relevant literature on nonprofit brand image and introduces the Michel and Rieunier’s (2012) work on nonprofit brand image. 


\section{CONCEPTUAL BACKGROUND}

Ample evidence highlights the importance of the explicit consideration of branding in a nonprofit context (e.g. Lovelock and Weinberg, 1990; Bennet and Sargeant, 2005; Ewing and

Napoli, 2005; Sargeant et al., 2008). Bennett and Sargeant (2005) argue that an excellent charity image influences consumer preferences toward charity brands, helps to increase donations and creates 'halo effects' in relation to other activities of the charity (p. 800). Despite the considerable evidence which emphasizes the importance of brand image in the nonprofit sector (e.g. Bennett and Gabriel, 2003; Stride, 2006; Sargeant and Woodliffe, 2007), research devotes little attention to the development of valid measurement of nonprofit brand image. However, Michel and Rieunier (2012) and other authors (e.g. Saxton, 1995; Sargeant, 1999; Bennet and Sargeant, 2003) emphasize the uniqueness of the nonprofit sector and the need to treat it differently from the for-profit sector, for example via the development of new instruments specifically for the nonprofit sector (Bennett and Sargeant 2005).

A common approach to capture brand image is via the use of brand personality (Aaker, 1997), which authors also use within the nonprofit context (Venable et al., 2005; Sargeant et al., 2008). Literature on commercial branding largely informs the conceptualization of nonprofit brand image, particularly brand personality measures such as Aaker's five-brand personality dimensions, i.e. sincerity, excitement, competence, sophistication, ruggedness. Venable et al. (2005) and Sargeant et al. (2008) borrow from the brand personality literature to capture nonprofit brand image and suggest that 'integrity' and 'nurturance' better serve the purpose of nonprofit differentiators in contrast to 'sincerity', 'excitement' and 'competence'. However, an 
important difference between brand personality and brand image calls for the separation of the two and the development of separate brand image measures. Whereas brand image reflects associations stored in consumers’ memory with regard to specific brand (Stride, 2006), brand personality reflects "a set of human characteristics associated with the brand” (Aaker, 1997, p. 347). Brand personality tends to serve and fulfil symbolic or self-expressive functions for consumers (e.g. Keller, 1993; Aaker, 1997), as such a brand is used by consumers to express and publicly identify different aspects of his/her self with that particular brand (e.g. Johar et al., 2005; Asperin, 2007). On the other hand, brand image represents consumers’ perceptions of what the brand stands for, and reflects the promises an organization gives to customers with regards to its products and/or services (e.g. Keller, 1993). As perceptions shape the actions of the consumers rather than reality (Boulding, 1956), brand image becomes a marketable investment for a company, helping organizations to differentiate from competitors and increase the likelihood of consumers purchasing the brand (Hsieh et al., 2004). Accordingly, organizations may manipulate brand image to initiate decision processes in their favor (Bendapudi et al., 1996).

Bennett and Gabriel (2003) propose a set of five underlying dimensions of nonprofit brand image namely, compassion, dynamism, idealism, focus on beneficiaries and being 'nonpolitical’. Empirical evidence demonstrates, however, that these nonprofit brand image dimensions only weakly predict intentions to donate (e.g. Venable et al., 2005; Sargeant et al., 2008). In contrast, Bennett and Gabriel’s (2003) scales have stronger predictive power, but contain predominantly 'commercial' personality variables, and do not tap into nonprofit aspects of brand image. The latter is something of a limitation given that charities and nonprofit organizations in general have unique image elements and require measures specific to the 
context (Bennett and Sargeant, 2003). A recent study by Michel and Rieunier (2012) proposes a four-dimensional solution to the conceptualization and measurement of nonprofit brand image, which demonstrates greater impact on donations, in terms of both time and money, relative to previous nonprofit brand image conceptualizations and measurements (Venable et al., 2005; Sargeant et al., 2008). In particular, Michel and Rieunier (2012) develop a nonprofit contextspecific set of brand image scales from data on five selected French and international humanitarian aid charities. The authors distinguish between brand personality and brand image and argue that brand image differentiates the role of functional and symbolic associations of the brand. As such, functional associations relate to organizational characteristics, the mission and tangible quality of the organization, whereas symbolic associations refer to the "abstract cognitions that translate the values of the organization, personality traits associated with the brand and even emotions” (Michel and Rieunier, 2012, p. 702). Based on previous conceptualizations and measurements of nonprofit brand image (e.g. Bennett and Gabriel, 2003; Venable et al., 2005; Sargeant et al., 2008), and following a scale development procedure involving qualitative and quantitative data collection methods, Michel and Rieunier (2012) develop a fundamentally different set of measures of nonprofit brand image in terms of the composition of the dimensions, namely usefulness, efficiency, affect and dynamism. Michel and Rieunier (2012) call for a validation of their scale in other contexts and with other samples in an attempt to advance the conceptualization and measurement of nonprofit brand image. In this study we attempt to first validate Michel and Rieunier’s (2012) nonprofit brand image scales in an alternative charity sector and country context (Study 1) and to propose, test and validate an improved conceptualization and measurement of nonprofit brand image (Studies $2 \& 3$ ). 


\section{STUDY 1: EVALUATION OF THE PSYCHOMETRIC PROPERTIES OF THE MICHEL AND RIEUNIER (2012) NONPROFIT BRAND IMAGE SCALES}

\subsection{Research Design}

To evaluate Michel and Rieunier's (2012) nonprofit brand image scales, the study applied the original instruments in the UK on two charities, Barnardo's and BBC Children in Need which vary on total income level. The authors selected the two charities via a pre-test whose purpose was to look for those sectors with strong ‘spontaneous recognition' from consumers. Those participants that scored high in spontaneous recognition were likely to have sufficient knowledge of the sector and charity, which was essential for the successful completion of the questionnaire. In order to assess spontaneous recognition, the pre-test asked 16 respondents to name the first charity sector (e.g. children charities) that they could think of excluding humanitarian aid charities, used by Michel and Reunier (2012) in their own study. Responses varied, with the highest percentage attributed to children's charities (37\% of respondents). To ensure that the public's recognition of both charities, and therefore a likelihood and ability to answer the questionnaire, a second pre-test was conducted. The second pre-test indicated good recognition of both charities. In addition, a pilot test with a convenience sample of 15 respondents resulted in minor adjustments to the questionnaire layout prior to the main launch. An online questionnaire advertised on social networking sites (e.g., Facebook and LinkedIn) and the University Internet discussion and announcement boards (administered by the University and directed towards students) instructed potential respondents to answer questions about both charities. The questionnaire had an easy to follow layout as well as question groupings, 
navigational paths and page design (Dillman, 2006). One hundred and fifty-one respondents successfully completed the questionnaire and provided responses to questions about both charities (Table 1).

Table 1 here.

\subsection{Analysis and Results}

Our data analytic strategies paralleled the specific goal of replicating Michel and Reunier’s (2012) previous results in a different charity sector and country. In order to do so, we followed the strategy undertaken by the authors to confirm the four-factor structure of the nonprofit brand image scales and submitted our data to exploratory factor analysis (EFA) and subsequently confirmatory factor analysis (CFA) analysis.

\subsubsection{Exploratory Factor Analysis}

First, our analysis involved two separate EFAs, one for each charity, using Principal axis factoring with an Oblimin oblique rotation with all 14 items of the Michel and Rieunier (2012) nonprofit brand image scale. Results returned 3 and 2 factor solutions for Barnardo's and BBC Children in Need respectively, instead of the 4-factor solution presented by Michel and Rieunier (2012) (see Table 2). Table 2 shows the pattern matrix for the Barnardo's and BBC Children in Need.

Table 2 here. 


\subsubsection{Confirmatory Factor Analysis}

Further analysis involved CFA using Lisrel 8.71 with maximum likelihood estimation (ML) for each of the two charities with all the original 14 items consisting of the 4 dimensions of the Michel and Rieunier’s (2012) nonprofit brand image scales. Following Michel and Rieunier’s (2012) procedure, all the items were specified to load on their respective factors only (Table 3). Therefore, the CFA models for Barnardo’s and BBC Children in Need contained the same constructs included in the original study regardless of the EFA results. We assessed model fit using the chi-square absolute fit statistic, together with several approximate fit indexes (the nonnormed fit index (NNFI), the comparative fit index (CFI), the standardized root mean square residual (SRMR), and the root mean square error of approximation (RMSEA)). The overall model fit assessed separately for each charity shows reasonable but not good fit for both charities. For the Barnardo's measure, the chi-square test of exact fit is significant $\left(\chi^{2}(\mathrm{df}=71)=164.84\right)$, the NNFI ( 0.92) and CFI (0.94) are acceptable, but the SRMR (0.07) and RMSEA (0.09) fail to reach recommended threshold levels. The fit for the BBC Children in Need measures is a little better, with chi-square significant $\left(\chi^{2}(\mathrm{df}=71)=138.96(71)\right)$, but with the NNFI (0.97), CFI (0.97), SRMR (0.05) and RMSEA (0.08) all achieving recommended threshold levels.

Table 3 here.

In order to ensure that common method variance (CMV) did not pose a threat to the study results, we adopted the Harman’s single-factor approach (Podsakoff et al., 2003). Harman’s single-factor approach involves the comparison of model fit for a model in which all items are forced to load on a single factor with the corresponding four factor model. Results of two 
Harman's single factor tests (i.e. one for Barnardo's sample and the other for the BBC Children in Need sample) show that the one-factor model (which is considered a proxy for a CMV factor) was a poor model in both cases: Barnardo's $\left(\chi^{2}(\mathrm{df}=77)=299.45\right.$; NNFI $=0.85$; CFI $=0.86$; SRMR $=0.09$ and RMSEA $=0.136)$ ) and BBC Children in Need $\left(\chi^{2}(\mathrm{df}=77)=261.58 ;\right.$ NNFI $=$ 0.93; $\mathrm{CFI}=0.94 ;$ SRMR $=0.09$ and RMSEA $=0.126$ ). Furthermore, the one-factor CMV model performs significantly worse relative to the four factor model (for both charities). Specifically, the improvement in model fit (i.e., reduction in $\chi^{2}$ ) on moving from the single factor (CMV) model to the more theoretically appealing four factor model is significant in both instances: for Barnardo's, $\Delta \chi^{2}(\Delta \mathrm{df})=64.61(6)(\mathrm{p}<.01)$, and for BBC Children in Need, $\Delta \chi^{2}(\Delta \mathrm{df})=122.62(6)$ $(\mathrm{p}<.01)$

Reliability assessment of the measures involved the use of indicators of convergent and discriminant validity, that is composite reliability (CR), average variance extracted (AVE), and highest shared variance (HSV) (Hansen et al., 2011) (Table 3). Fornell and Larcker (1981) suggest that a critical value of 0.5 and above for AVE for each scale is an indicator of the convergent validity of the construct. As can be seen in Table 3, AVE values for the dimensions of Usefulness and Efficiency for both charities do not produce the recommended threshold. AVE values for Affect and Dynamism return acceptable levels of 0.51 and 0.71 for Barnardo's and 0.66 and 0.67 for BBC Children in Need respectively. Composite reliability (CR) values for each scale indicated that the CR values for all the scales in both charities are well above the critical value of 0.60 (Bagozzi and Yi, 1988) (Table 3).

To assess discriminant validity, we compared the AVE scores of each construct with the shared variances (i.e. squared of all construct correlations) (Fornell and Larcker, 1981; Hair et al., 
2010). An analysis of the AVEs and squared correlations between measures, for both Barnardo's and BBC Children in Need, shows that every measure experiences discriminant validity problems (see Table 4), since its AVE is smaller than at least one (and usually more than one) pair of squared correlations.

Table 4 here.

The results of Study 1 highlight the poor performance of Michel and Rieunier's nonprofit brand image scales, which fail to provide the expected factor structures in EFA and CFA. In addition, there is dovetailing evidence of discriminant validity problems with AVE values below the recommended level (e.g. 0.50); and there are numerous occasions where the squared correlations between constructs exceed those constructs' AVEs and, in many cases, the squared correlations are often considerably larger than the AVEs. As a result, if the measures, as they stand, were to be used by charities or scholars to measure their brand image, the results would be uninterpretable or meaningless. This provides a strong motive to work at refining the scales via improving the conceptualization of nonprofit brand image and its measurement, which represents the objectives of studies $2 \& 3$. 


\section{STUDY 2: TOWARDS A BETTER CONCEPTUALIZATION AND MEASUREMENT OF NONPROFIT BRAND IMAGE}

Given the measurement incomparability of Michel and Rieunier (2012) scales in the context of this research, which indicates that additional associations maybe needed to capture nonprofit brand image successfully, Study 2 focuses on improving the conceptualization and measurement of nonprofit brand image by reassessing the domain of the construct. Blalock (1982) suggests that measurement incomparability maybe the result of poor conceptualization and/or measurement of a theory or construct in a new domain. Hence, study 2 complements Michel and Rieunier’s (2012) conceptualization of nonprofit brand image with additional associations (i.e. improving content validity) based on existing literature and subsequently tests the scales using additional data in line with previous common procedures and approaches (Hinkin, 1995). In an attempt to improve the conceptualization of nonprofit brand image put forward by Michel and Rieunier (2012) (and therefore its content validity) we conducted a literature review of previous nonprofit brand image and brand personality sources. We focused on identifying brand associations, in line with the domain of specificity adopted by Michel and Rieunier (2012) ${ }^{1}$. Michel and Rieunier (2012) develop their conceptualization and measures in France, following qualitative interviews with French donors and non-donors; it seems plausible that additional items may be required to reflect associations to nonprofit brand image for Native English

\footnotetext{
${ }^{1}$ The objective of Study 2 is not to generate a completely new measurement of nonprofit brand image but to improve that of Michel and Rieunier (2012) as this is currently the only scale, which captures associations within the nonprofit context, instead of adapting for-profit brand associations in the charity context.
} 
speaking respondents, thus to improve content validity. The literature review identified 29 additional items to the ones by Michel and Rieunier (2012), and highlighted particularly that, ethical associations and associations pertaining to how reliable a charity is, are key elements of nonprofit brand image.

\subsection{Ethicality and Reliability as Dimensions of Nonprofit Brand Image}

Ethicality encompasses a set of moral principles that guide individual and organizational behavior. According to Jones (1991) ethical behaviors are those that are "legal and morally acceptable to the larger community" (p. 628) (also Nguyen and Biderman, 2008). Previous research indicates that consumers form associations or considerations that pertain to the ethics or morality of their own behaviors or actions (e.g. Crane, 2001) as well as the behaviors of others (e.g., organizations), which form the overall image of an organization (Keller, 1993; Schmitt, 2012). In the context of nonprofit organizations, previous research equals charitable giving as an ethical or moral issue or behavior and one with high social consensus (Ray, 1998; Reynolds and Ceranic, 2007), as it has consequences for others [in need] and involves choice or volition on the part of the decision maker (Jones, 1991; Velasquez and Rostankowski, 1985). Sargeant and Lee (2004) and Sargeant et al. (2008) argue about the perceived ethics of charities and other nonprofit organizations, emphasizing that charity values and activities are centered on benevolence in a way that differentiates them from their for-profit counterparts. For example, the way charities are organized and managed imbue moral principles and benevolent attributes such

\footnotetext{
2 ‘Ethical' and 'Moral’ are used as synonymous (Jones, 1991).
} 
as being fair, honest and ethical (Sargeant et al., 2008). Additionally, according to Sargeant et al. (2008) and Bennett and Barkensjo, (2005) closely related to the notion of charity, is the notion of being trustworthy, reliable and responsible. Individuals perceive charities and other nonprofit organizations as reliable and responsible because they are deeply concerned with the welfare of others (Bennett and Barkensjo, 2005), suggesting that these notions are an integral part of nonprofit brand image.

Further, ethical issues faced by charities and other nonprofit organizations have a direct effect on the decrease of public trust and hence consumers' charitable contributions (Deshpande, 1996; Sargeant and Lee, 2004; Sargeant et al., 2008). In this sense, consumers expect charities to be ethical, trustworthy and reliable and this image impacts their preferences and donations (Sargeant and Lee, 2004). On the basis of this stream of research (Sargeant et al. 2008; Bennett and Barkensjo, 2005; Sargeant and Lee, 2004; Ray, 1998; Reynolds and Ceranic, 2007) this study argues that ethicalilty and reliability represent fundamental associations which reflect the brand image of charities (e.g. Keller 1993), since consumers' perceive that charities will operate and use donations ethically and reliably to help others in need.

\subsection{Research Design}

Two expert academics assessed the items drawn from the literature, without a priori categorization or a classification schema, in terms of their value in capturing the image of an association (e.g. functional and/or symbolic, type etc.) in line with previous research (Keller, 1993; Aaker, 1997; Michel and Rieunier, 2012). All 43 items remained and were part of the 
subsequent research design in an attempt to ensure content adequacy and validity (Hinkin, 1995; Stone, 1978) and allow the possibility of additional dimensions to emerge as elements of nonprofit brand image.

Table 5 here.

Data collection involved questionnaires using a sample of college students to measure nonprofit brand image, which included 43 items measured on 7-point Likert-type scales. The questionnaire included different format scale anchors to minimize the potential for CMV (Dillman, 2006). The questionnaire was self-administered, anonymous and it did not record personal data so as to minimize concerns regarding social desirability bias (Nederhof, 1985). Questions involved Barnardo's charity only. Instructions to respondents emphasized that they should complete the questionnaire only if they had knowledge of the charity, hence responses which indicated no prior knowledge of Barnardo's were excluded. The reason for choosing Barnardo's as opposed to both charities is that Barnardo's popularity and size fit the aim of the study (i.e. improvement of the scale) better in terms of response rates, charity recognition and knowledge. The choice of the sample was driven by the focus of the study, which aimed to examine the scale on a theoretical level, and it is in line with previous research (e.g. Sternthal et al., 1994; Koschate-Fischer et al., 2012) that suggests homogenous samples like college students are able to provide information about the covariances between the items in the item pool; so they represent a convenient sample to generate data to allow preliminary measurement assessment to take place. Additionally, even though students do not have high levels of disposable income, they are making donations in time, apparel, and books (e.g. ST-ANDREWS, 2008). Having said 
that, $69 \%$ of the student respondents in our study would consider to or have donated money to Barnardo’s. Of the 325 in-class surveys distributed, 200 were fully completed yielding a response rate of $61.54 \%$ (Table 6).

Table 6 here.

\subsection{Data analysis and Results}

Analysis consisted of EFA on 43 items, using Principal axis factoring with an Oblimin oblique rotation. Following removal of 4 items that failed to load on any of the factors (indispensable, civic-minded, serious, inspiring) and 1 item that loaded on a single, separate factor (pioneering), the analysis indicated a clean 6-factor solution with no cross-loadings. The six dimensions were named as: Usefulness, Efficiency, Affect, Dynamism, Reliability, and Ethicality in line with Venable et al. (2005), Sargeant et al. (2008) and Michel and Rieunier (2012). The two new dimensions Reliability, and Ethicality are consistent with previous research on the nonprofit domain (e.g., Sargeant et al., 2008; Venable et al., 2005).

The remaining 38 items were entered into a CFA analysis with a specified 6-factor model representing the nonprofit brand image measures. Further assessments involved reliability of scales (i.e. CR and AVE). The initial CFA results returned a mediocre model fit, with a significant chi-square $\left(\chi^{2}(687)=1478.22\right)$, but with moderate to reasonable approximate fit information (NNFI (0.97) and CFI (0.97) exceed recommended minimum values, but the SRMR (0.06) and RMSEA (0.08) exceed the recommended maximum threshold of .05). Given that it is 
not uncommon in CFA model assessment for the implied model to not fit the observed data well on first estimation (Kelloway, 1998) (in this case, poor RMSEA and SRMR values), further trimming of the scales was undertaken. Accordingly, we went through an iterative process in which we identified items with large correlated errors, assessed whether they were essential to the conceptual meaning of the constructs, and in those cases where the items were deemed nonessential, deleted them from the model (Anderson and Gerbing, 1988). The final measurement model yielded excellent fit: although chi-square remained significant, the approximate fit information demonstrates very good fit on all fronts with all indicators performing within recommended benchmark levels $\left(\chi^{2}(144)=200.69, \mathrm{NNFI}=0.99, \mathrm{CFI}=0.99, \mathrm{SRMR}=0.04\right.$ and RMSEA $=0.04$ ). Table 7 provides a full list of the items for the 6 dimensions of nonprofit brand image, their respective factor loadings, descriptive statistics, Cronbach's $\alpha$ values, CR and AVE values.

Table 7 here.

\subsubsection{Common Method Variance and Reliability Tests}

To assess CMV, the Harman's single factor test was used, which indicated that CMV was not a threat: the CMV single factor model fit is poor $\left(\chi^{2}(230)=1405.83\right.$; NNFI $=0.87$; CFI $=$ 0.88; SRMR $=0.111$ and RMSEA $=0.166$ ), and the improvement in model fit on moving from the CMV single factor model to the six-factor model is significant $\left(\Delta \chi^{2}(\Delta d f)=1205.14(86)(p\right.$ $<.01)$ ). Based on the assessment of CMV, it can be concluded that CMV does not pose a threat in the current study. 
With respect to reliability, CR values are all adequate, exceeding the critical value of 0.60 in all instances (Bagozzi and Yi, 1988). The same situation is observed for Cronbach's alpha values, which all exceed Nunnally's (1978) 0.70 recommended minimum value (Table 7). Interitems correlations show strong internal consistency, with all the items correlating strongly, hence meeting the minimum recommended threshold value of 0.35 (Hair et al., 2010) (Table 8). In addition, factor loadings for all 6 subscales, were high and significant $(\mathrm{p}<0.01)$, obtaining significant t-values and satisfying the criteria for convergent validity (Fornell and Larcker, 1981; Bagozzi and Yi, 1988). Further, convergent validity assessment through the average variance extracted (AVE) indicates that all the values for AVE exceed the recommended threshold of 0.5 (Fornell and Larcker, 1981). To assess discriminant validity, we examine the HSV by comparing the AVE scores of constructs with the square of correlations between constructs (Fornell and Larcker, 1981) (see Table 9; Study 2: Barnardo’s). All AVE estimates for each of the constructs is greater than the squared correlation estimate for each pair of construct and hence, we achieve discriminant validity.

Table 8 here.

Table 9 here.

\subsubsection{Nomological Validity}

The final assessment of construct validity involves evaluating the validity of the measures by examining whether the scales correlate with other variables which they should be associated 
with. Previous research argues that a positive charity image increases charitable donations (Webb et al., 2000), and in line with Michel and Rieunier (2012), the study used intention to donate time and money to charity as dependent variables in a multiple regression. The results are statistically significant (Table 10) and indicate that all linear relationships are positive $(\mathrm{p}<.05)$. In particular, the results indicate that all facets of nonprofit brand image simultaneously predict intentions to donate money $\left(\mathrm{R}^{2}=0.38\right)$ and time $\left(\mathrm{R}^{2}=0.39\right)$ to Barnardo's, confirming previous assertions that a positive image increases donations to charity (Webb et al., 2000; Michel and Rieunier, 2012).

Table 10 here.

\section{STUDY 3: GENERALIZABILITY OF THE NEW MEASURES}

The new measures presented in study 2 were developed and assessed on a sample of students using one charity. In order to provide more information on the generalizability of the measures to other samples and other charities, the authors collected additional data from a nonstudent sample. Specifically, the final questionnaire developed in study 2 was administered faceto-face using a (convenient) mall-intercept approach. This time, the chosen charity was the National Society for the Prevention of Cruelty to Children (NSPCC). In total, 200 respondents completed the questionnaire. Once again, in order to assess the CMV, the Harman's single factor test was used. The CMV single factor model fit is poor $\left(\chi^{2}(138)=8667.19\right.$; NNFI $=0.76$; CFI $=$ 
0.79; SRMR $=0.139$ and RMSEA $=0.536$ ), and the improvement in model fit on moving from the CMV single factor model to the six-factor model is significant $\left(\Delta \chi^{2}(\Delta \mathrm{df})=8260.45(37)\right)$. To add rigor to the CMV assessment, we complimented it with a second CMV approach - the marker variable test. In the marker variable test, one incorporates a measure in the measuring instrument that is not theoretically associated with the measures being assessed (in the current case, the non-profit brand image measures). Common method bias might be a problem if the marker item displays large correlations with the measures being developed (Lindell and Whitney, 2001), however, an assessment of correlations indicates that all the correlations are nonsignificant and low. The results of the second test also indicate that CMV does not pose a threat for this study. Finally, a test for social desirability bias was conducted using a 6-item social desirability index (Luo, et al., 2007). The correlations between the social desirability score and the brand image measures are all non-significant, indicating that social desirability is not a major influence on respondents' answers.

The CFA results for the measure returned very good model fit $\left(\chi^{2}(175)=406.74\right.$; NNFI $=0.98 ; \mathrm{CFI}=0.98 ; \mathrm{SRMR}=0.04$ and RMSEA $=0.07)$. An examination of the CRs and AVEs shows that they are all above the recommended thresholds of .60 and .50, respectively (Bagozzi and Yi, 1988). In addition, all constructs exhibit discriminant validity (see Table 9, Study 3: NSPPC) since all AVE scores are greater than the square of the correlations between each pair of constructs (Fornell and Larcker 1981). Table 7 provides a full list of the items for the six dimensions of nonprofit brand image for studies 2 and 3, each item's respective factor loading, and the descriptive statistics, Cronbach's $\alpha, \mathrm{CR}$ and AVE values for each of the measures. Finally, statistically significant results from multiple regression (Table 11) show nomological 
validity since all linear relationships are positive $(\mathrm{p}<.05)$, with the results indicating that all facets of brand image simultaneously predict intentions to donate money $\left(\mathrm{R}^{2}=0.51\right)$ and time $\left(\mathrm{R}^{2}=0.54\right)$ to the NSPCC.

Table 11 here.

\section{DISCUSSION AND IMPLICATIONS}

In view of the scarcity of measures that capture nonprofit brand image, the importance of the notion of brand image for the nonprofit sector, and following Michel and Rieunier's (2012) assertion that the development and validation of scales that correctly reflect the "characteristics of the nonprofit world” (p. 701) is long due, this study undertakes the task to validate (Study 1) and further improve (Studies 2 and 3) the nonprofit brand image scales Michel and Rieunier (2012) propose via data from the UK on three children's charities. Our study builds on, and extends the work of Michel and Rieunier (2012) but also complements previous research in the domain of nonprofit brand image (e.g. Venable et al., 2005; Sargeant et al., 2008).

The results of study 1 indicated several problems with Michel and Rieunier's scale's psychometric properties, in both charity contexts in which the measures were administered. Discrepancies in the factor solutions for the EFA analysis for both charities show that results fail to support the four-factor solution that Michel and Rieunier (2012) report in their study. This result provides the impetus for study 2, in which effort is made in order to improve the nonprofit brand image measures, and provide a stronger theoretical and methodological contribution to a 
particularly interesting field of research. In an attempt to improve the content validity of Michel and Rieunier's instrument, study 2 provides support for a six-dimension structure of nonprofit brand image, which extends the current theory and measures in the nonprofit brand image domain. In particular, and in line with previous literature we propose that ethicality and reliability are important dimensions capturing nonprofit brand image (Ray, 1998; Reynolds and Ceranic, 2007; Sargeant and Lee, 2004; Sargeant et al., 2008), in addition to affect, dynamism, usefulness and efficiency (Michel and Rieunier, 2012). EFA and CFA results from studies 2 and 3 suggest that nonprofit brand image is better captured using these six dimensions instead of the four initial dimensions of Michel and Rieunier (2012). Hence, the measures developed and reported in the studies 2 and 3 support the notion that individuals' perceptions of nonprofit image involve associations regarding usefulness, efficiency, affect, dynamism, reliability and ethicality. Additionally, the results indicate that these dimensions correlate with intentions to donate money and time at significant levels and simultaneously. Most interestingly, the explanatory power of the nonprofit dimensions in predicting intentions to donate money and time improve substantially in study 3 relative to study 2 . The new measures also show a substantial increase in explanatory power (e.g. $\mathrm{R}^{2} \mathrm{~s}$ of $51 \%$ and $54 \%$ for money and time donations respectively) when compared to the original study of Michel and Rieunier (2012), where $\mathrm{R}^{2} \mathrm{~s}$ reported only $31 \%$ and $24 \%$ in terms of predicting intention to donate money and time, respectively. The two new dimensions to the domain of nonprofit brand image are reliability and ethicality, and both can be seen to impact intentions to donate money and time at a significant level (Tables 10 and 11) suggesting that individuals form perceptions and images on the basis of ethical and moral 
principles, and that individuals expect charities to be ethical and righteous which affects their money and time donations.

\subsection{Theoretical Implications}

This research contributes to theory by putting forward an improved conceptualization of nonprofit brand image consisting of 6 dimensions namely usefulness, efficiency, affect, dynamism, reliability and ethicality. Relative to the original conceptualization by Michel and Rieunier (2012), this study suggests that the notions of reliability and ethicality are theoretically linked to nonprofit brand image, suggesting that consumers derive ethical or moral associations in forming images of charities, as well as associations about the reliability of a specific charity. Our conceptualization complements previous research (Malloy and Agarwal, 2001; Sargeant et al., 2008), which highlights the importance of morality in shaping images of charity brands, and so contributes not only to the nonprofit brand image literature stream, but more broadly integrates the notion of ethics in the conceptualization of brand image. Specifically, this conceptualization highlights that charities are perceived in terms of their moral principles, which are grounded on benevolence and care for the welfare of others. Similarly, consumers view reliability or trustworthiness to be a key element of what charities represent and attempt to achieve. To this end, nonprofit brand image is understood better by associations formed by consumers pertaining to the usefulness, efficiency, dynamism, affect, reliability and ethicality of charitable/nonprofit organizations, which impact their intention to donate money and time. 


\subsection{Methodological Implications}

Despite the importance of a positive brand image for nonprofit organizations, previous scales for assessing the nonprofit brand image do not exhibit acceptable reliability and validity when applied in the domain of nonprofit children's charities in the UK. Inability to provide comparability across contexts and population groups leads to potential issues of measurement generalizability (Blalock, 1982). In such instances, one source of difficulties could be connected to invalidity of previous measures or poor definition of the nonprofit brand image in the first place (Cowles and Crosby, 1986). By tapping into these issues, we provide two main methodological contributions. First, current research adds to the literature by answering the call for further validation of Michel and Rieunier's (2012) nonprofit brand image scale in a different market and charity sector. Second, we re-define the domain of the nonprofit brand image through the provision of a richer conceptualization based on which we develop a new reliable and valid scale for the measurement of nonprofit brand image that reflects each of the six defined dimensions of nonprofit brand image. We further validate the newly constructed scale in study 3 . The results indicate that the instrument consisting of six dimensions has a higher explanatory power, than that of Michel and Rieunier (2012), predicting over 50\% of variance in consumers' intention to donate money and time to children charities. Through a series of studies and tests we demonstrate that the set of nonprofit scales possess reliability, content and predictive validity. This instrument represents a methodological contribution to measuring nonprofit brand image and one that possesses construct validity. These results give us the confidence that the scale could be successfully generalized to other nonprofit and charity brands. 


\subsection{Managerial Implications}

The need of charities to rely on image as a marketing tool to compete for resources in the form of individual donations of money, time and kind (e.g. books, apparel) warrants the research attention on nonprofit brand image. Unless appropriate definitions and measures are developed it would not be possible for nonprofit organisations to properly assess their brand image. This study offers improved measures of nonprofit brand image that highlight the necessity of charities to consider the image of their brand in the context of several image dimensions. Specifically, charities should not only communicate to consumers that they are useful, efficient, likeable and dynamic but also they should focus on the 'ethical' and 'reliable' associations and promote those in their campaigns. By identifying and measuring these six-components, both researchers and non-profit organizations can now validly assess how each of these dimensions impact donors' behavior. For example, charities should emphasize in their campaigns that they are doing 'the right or the moral thing' (e.g. ethicality) by pursuing their cause and being innovative in doing so (e.g. protecting/helping children or helping to fight a disease) and that consumers should trust them as they are responsible and reliable. In doing so, charities can incorporate information (cognitive elements) about how they fund projects from public donations in an attempt to demonstrate to consumers that they are responsible, reliable but also efficient and useful in achieving their mission. Thus, charitable campaigns communicating all 6 dimensions of nonprofit (usefulness, efficiency, affect, dynamism, reliability and ethicality) brand image are more persuasive and are collectively stronger in influencing consumer monetary donations as well as donations in time. 


\subsection{Limitations and Further Research}

Our study like any other is not free of limitations. While in line with previous research, study 2 uses a student sample to further improve the Michel and Rieunier (2012) nonprofit brand image scale. This may have affected the predictive validity of our improved scale, however study 3 which used a non-student sample significantly improved the explanatory power and generalizability of the nonprofit brand image scales. Nevertheless, replication in other samples will help add confidence in the measures developed. For instance, research could be undertaken to assess if the measures are generalizable to different national subpopulations and groups, and in other countries, both similar to the United Kingdom, but also different from it.

Beyond the issue of sample composition, the current paper's studies use data that relate to the image of three children's charities. Although we provide evidence for scale reliability and validity in study 3, we acknowledge that there is an imperative to assess whether the measures are valid when applied to different types of charities and other varied nonprofit organizations (e.g., religious groups, community sports groups, or nonprofit educational entities). It may well be that, in some instance, a measurement instrument, when applied to other populations and types of nonprofit organizations, might actually tap into different constructs (Cowles and Crosby, 1986). Hence, we encourage further research in this direction. This would help further establish the validity of this newly developed noprofit brand image set of scales and potentially lead to further refinement. 
The program of research presented in the current paper has several strengths, including the use of diverse samples to develop and validate the measures developed, and tests for biases of various sorts, including common method biases and social desirability biases. That said, the discriminant validity of the measures needs to be further assessed to ensure the latter's distinctiveness from other brand-related notions such as brand likeability (we thank a reviewer for suggesting this research path). Additionally research could further examine the nomological validity of the nonprofit brand image measures through examination of (a) additional facets of consumers' intention to donate in kind (e.g. apparel, books etc.), (b) observed behavior (e.g., actual donations), and (c) post-donation outcomes (such as donor satisfaction). Another avenue for further research is the examination of the potential existence of moderators shaping the relationships between nonprofit brand image dimensions and donations. For example, donor’s traits, such as interest in the charity, interest in the charitable "sector" the charity operates in, and their history of charitable giving and charitable work, may enhance or dampen the relationships studied here. And of course, respondent personality may differentially shape how image perceptions drive potential donor responses to image. 


\section{References}

Aaker, J. L. (1997). Dimensions of brand personality. Journal of Marketing research, 34, 347-356.

Anderson, J. C., \& Gerbing, D. W. (1988). Structural equation modeling in practice: A review and recommended two-step approach. Psychological bulletin, 103(3), 411-423.

Asperin, A. E. (2007). Exploring brand personality congruence: Measurement and application in the casual dining restaurant industry. ProQuest.

Bagozzi, R. P., \& Yi, Y. (1988). On the evaluation of structural equation models. Journal of the academy of marketing science, 16(1), 74-94.

Balmer, J. M. (1995). Corporate branding and connoisseurship. Journal of General Management, 21, 24-24.

Balmer, J. M. (1998). Corporate identity and the advent of corporate marketing. Journal of Marketing Management, 14(8), 963-996.

BBC (2013). Available at: http://backbritainscharities.org.uk/ [Accessed 01 June 2013]

Bendapudi, N., Singh, S. N., \& Bendapudi, V. (1996). Enhancing helping behavior: An integrative framework for promotion planning. The Journal of Marketing, 60(3), 33-49.

Bennett, R., \& Gabriel, H. (2003). Image and reputational characteristics of UK charitable organizations: An empirical study. Corporate reputation review, 6(3), 276-289.

Bennett, R., \& Barkensjo, A. (2005). Relationship quality, relationship marketing, and client perceptions of the levels of service quality of charitable organisations. International Journal of Service Industry Management, 16(1), 81-106. 
Bennett, R., \& Sargeant, A. (2005). The nonprofit marketing landscape: guest editors' introduction to a special section. Journal of Business Research, 58(6), 797-805.

Blalock, H. M. (1982). Conceptualization and measurement in the social sciences. Beverly Hilis, CA: Sage Publications.

Boulding, K. E. (1956). The Image. University of Michigan Press: Ann Arbour.

Chapleo, C. (2013). Brand Infrastructure in Non Profit Organizations; what supports successful brand building? Journal of Marketing Communications.

Charities Aid Foundation (2012). Available at: www.charitytrends.org/KeyCharts.aspx [Accessed 01 June 2013]

Charity Commission (2013). Available at: http://www.charitycommission.gov.uk/aboutcharities/sector-facts-and-figures/ [Accessed 01 June 2013]

Cheung, C. K., \& Chan, C. M. (2000). Social-cognitive factors of donating money to charity, with special attention to an international relief organization. Evaluation and Program Planning, 23(2), 241-253.

Cowles, D., \& Crosby, L. A. (1986). Measure validation in consumer research: A confirmatory factor analysis of the voluntary simplicity lifestyle scale. Advances in Consumer Research, 13(1), 392-397.

Crane, A. (2001). Unpacking the ethical product. Journal of Business Ethics, 30(4), 361-373.

Deshpande, S. P. (1996). Ethical climate and the link between success and ethical behavior: An empirical investigation of a non-profit organization. Journal of Business Ethics, 15(3), 315320. 
Dillman, D. A. (2006). Mail and internet surveys: The tailored design method (Vol. 2). New York: Wiley.

Ewing, M.T. \& Napoli, J. (2005). Developing and validating a multidimensional nonprofit brand orientation scale. Journal of Business Research, 58(6), 841-853.

Fornell, C., \& Larcker, D. F. (1981). Evaluating structural equation models with unobservable variables and measurement error. Journal of marketing research, 18, 39-50.

Gardner, B. B., \& Levy, S. J. (1955). The product and the brand. Harvard Business Review, 33(2), 33-39.

Hair, J. F., Black, W. C., Babin, B. J., Anderson, R. E., \& Tatham, R. L. (2010). Multivariate data analysis (Vol. 7). Upper Saddle River, NJ: Prentice Hall.

Hansen, J. D., Deitz, G. D., Tokman, M., Marino, L. D., \& Weaver, K.M. (2011). Cross national invariance of the entrepreneurial orientation scale. Journal of Business Venturing, 26, $61-78$.

Henley, T. K. (2001). Integrated marketing communications for local nonprofit organizations: Communications tools and methods. Journal of Nonprofit \& Public Sector Marketing, 9(1-2), $157-168$.

Hinkin, T. R. (1995). Review of scale development practices in the study of organizations. Journal of Management, 21(5), 967-988.

Hsieh, M. H., Pan, S. L., \& Setiono, R. (2004). Product-, corporate-, and country-image dimensions and purchase behavior: a multicountry analysis. Journal of the Academy of Marketing Science, 32(3), 251-270. 
Hudson, J. (2008). The branding of charities. In The Routledge Companion to Nonprofit Marketing, Sargeant A, Wymer W (eds). Routledge: New York, NY. Johar, G. V., Sengupta, J., \& Aaker, J. L. (2005). Two roads to updating brand personality impressions: Trait versus evaluative inferencing. Journal of Marketing Research, 42(4), 458-469.

Jones, T. M. (1991). Ethical decision making by individuals in organizations: An issuecontingent model. Academy of management review, 16(2), 366-395.

Juntunen, M., Juntunen, J., \& Autere, V. (2013). Co - creating nonprofit brand equity. International Journal of Nonprofit and Voluntary Sector Marketing, 18(2), 122-132.

Keller, K. L. (1993). Conceptualizing, measuring, and managing customer-based brand equity. The Journal of Marketing, 57(1), 1-22.

Koschate-Fischer, N., Adamantios Diamantopoulos, A., \& Katharina Oldenkotte, K. (2012). Are consumers really willing to pay more for a favorable country image? A study of country-oforigin effects on willingness to pay. Journal of International Marketing, 20(1), 19-41.

Levy, S.J., \& Glick, I.O. (1973). Imagery and Symbolism. In S.H. Britt (Ed.), Marketing Manager's Handbook (pp. 961-969). Chicago: Dartnell.

Lindell, M. K., \& Whitney, D. J. (2001). Accounting for common method variance in crosssectional research designs. Journal of applied psychology, 86(1), 114.

Lovelock, C. H., \& Weinberg, C. B. (1990). Public and non-profit marketing: themes and issues for the 1990s. In Lovelock, C.H. and Weinberg, C.B. (Eds), Public and Nonprofit Marketing:Readings and Cases ( $2^{\text {nd }}$ ed.). The Scientific Press, San Francisco, CA, 3-14. .

Malloy, D. C., \& Agarwal, J. (2001). Ethical climate in nonprofit organizations: Propositions and implications. Nonprofit Management and Leadership, 12(1), 39-54. 
Michel, G., \& Rieunier, S. (2012). Nonprofit brand image and typicality influences on charitable giving. Journal of Business Research, 65(5), 701-707.

Mort, G. S., Weerawardena, J., \& Williamson, B. (2007). Branding in the non-profit context: the case of Surf Life Saving Australia. Australasian Marketing Journal, 15(2), 108-119.

Nederhof, A. J. (1985). Methods of coping with social desirability bias: A review. European Journal of Social Psychology, 15, 263-280.

Nguyen, N. T., \& Biderman, M. D. (2008). Studying ethical judgments and behavioral intentions using structural equations: Evidence from the Multidimensional Ethics Scale. Journal of Business Ethics, 83(4), 627-640.

Nunnally, J. (1978). Psychometric theory. New York, NY: McGraw Hill.

Paivio, A. (1969). Mental imagery in associative learning and memory. Bobbs-Merrill.

Park, C. W., Jaworski, B. J., \& Maclnnis, D. J. (1986). Strategic brand concept-image management. The Journal of Marketing, 50, 135-145.

Podsakoff, P. M., MacKenzie, S. B., Lee, J., \& Podsakoff, N. P. (2003). Common method biases in behavioral research: A critical review of the literature and recommended remedies. Journal of Applied Psychology, 88(5), 879-903.

Pope, J. A., Isely, E. S., \& Asamoa-Tutu, F. (2009). Developing a marketing strategy for nonprofit organizations: An exploratory study. Journal of Nonprofit \& Public Sector Marketing, 21(2), 184-201.

Ray, L. (1998). Why we give: Testing economic and social psychological accounts of altruism. Polity, 30, 383-415. 
Reynolds, S. J., \& Ceranic, T. L. (2007). The effects of moral judgment and moral identity on moral behavior: an empirical examination of the moral individual. Journal of Applied Psychology, 92(6), 1610-1624.

Romaniuk, J., \& Nenycz-Thiel, M. (2013). Behavioral brand loyalty and consumer brand associations. Journal of Business Research, 66(1), 67-72.

Sargeant, A. (1999). Charity giving: Towards a model of donor behavior. Journal of Marketing Management, 15, 215-238.

Sargeant, A., \& Lee, S. (2004). Trust and relationship commitment in the United Kingdom voluntary sector: Determinants of donor behavior. Psychology \& Marketing, 21(8), 613-635.

Sargeant, A., \& Woodliffe, L. (2007). Gift giving: an interdisciplinary review. International Journal of Nonprofit and Voluntary Sector Marketing, 12(4), 275-307.

Sargeant, A., Ford, J. B., \& Hudson, J. (2008). Charity brand personality: the relationship with giving behavior. Nonprofit and Voluntary Sector Quarterly, 37(3), 468-491.

Saxton, J. (1995). A strong charity brand comes from strong beliefs and values. Journal of Brand Management, 2(4), 211-220.

Schmitt, B. (2012). The consumer psychology of brands. Journal of Consumer Psychology, 22(1), 7-17.

ST-ANDREWS (2008). http://www.st-andrews.ac.uk/environment/news/charitydonations/

[Accessed 18 September 2013]

Sternthal, B., Alice M. Tybout, A. M., \&. Calder, B. J. (1994). Experimental design:

Generalization and theoretical explanation. In Bagozzi, R. P. (Ed.), Principles of Marketing Research,. Cambridge, MA: Blackwell Publishers, 195-223. 
Stone, E, (1978), Research methods in organizational behavior. Glenview, IL: Scott, Foresman.

Stride, H. (2006). An investigation into the values dimensions of branding: implications for the charity sector. International Journal of Nonprofit and Voluntary Sector Marketing, 11(2), 115-124.

Stride, H., \& Lee, S. (2007). No Logo? No Way. Branding in the Non-Profit Sector. Journal of Marketing Management, 23(1-2), 107-122.

Velasquez, M. G., \& Rostankowski, C. (1985). Ethics: Theory and Practice. Prentice Hall, Englewood Cliffs, NJ.

Venable, B. T., Rose, G. M., Bush, V. D., \& Gilbert, F. W. (2005). The role of brand personality in charitable giving: an assessment and validation. Journal of the Academy of Marketing Science, 33(3), 295-312.

Waters, R. D., \& Jones, P. M. (2011). Using video to build an organization's identity and brand: A content analysis of nonprofit organizations' YouTube videos. Journal of Nonprofit \& Public Sector Marketing, 23(3), 248-268.

Webb, D. J., Green, C. L., \& Brashear, T. G. (2000). Development and validation of scales to measure attitudes influencing monetary donations to charitable organizations. Journal of the Academy of Marketing Science, 28(2), 299-309. 


\section{Tables}

Table 1

Respondents Profile

\begin{tabular}{lll}
\hline & n & Percentage \% \\
\hline Gender & & \\
$\quad$ Male & 52 & 34.4 \\
$\quad$ Female & 99 & 65.6 \\
Age & & \\
$\quad 20$ and under & 16 & 10.6 \\
$21-30$ & 61 & 40.4 \\
$31-40$ & 10 & 6.6 \\
$41-50$ & 22 & 14.6 \\
51 and over & 42 & 27.8 \\
Income & & \\
Less than $£ 10,000$ & 61 & 40.4 \\
$£ 10,000-£ 20,000$ & 31 & 20.5 \\
$£ 20,000-£ 30,000$ & 30 & 19.9 \\
$£ 30,000-£ 40,000$ & 11 & 7.3 \\
$£ 40,000$ plus & 18 & 11.9 \\
\hline
\end{tabular}

Table 2

EFA results for Barnardo's and BBC Children in Need

\begin{tabular}{ll|lll|lc}
\hline Scales & Items & \multicolumn{2}{c}{ Barnardo's } & \multicolumn{2}{c}{ BBC Children in Need } \\
\hline \multirow{2}{*}{ Usefulness } & Indispensable & & 2 & 3 & 1 & 2 \\
& Useful & & & & 0.57 \\
& Civic-minded & & & 0.90 & 0.60 & \\
Efficiency & Efficient & 0.53 & & & & 0.43 \\
& Serious & 0.66 & & & 0.77 \\
& Well-managed & 0.90 & & & 0.41 \\
& Excellent service & 0.40 & & & 0.69 \\
& Uses assets wisely & 0.53 & & & 0.58 \\
Affect & Friendly & & -0.5 & & 0.94 & \\
& Generous & 0.42 & & 0.66 & \\
& Warm & & -0.61 & 0.66 & \\
Dynamism & Engaging & & -0.73 & & 0.83 & \\
& Modern & & -0.87 & 0.82 & \\
& Innovative & & -0.75 & & \\
\end{tabular}


Table 3

Model fit measures, factor loadings and scale properties

\begin{tabular}{|c|c|c|c|c|c|c|c|c|}
\hline Model & \multicolumn{2}{|c|}{$\chi^{2}$} & df & NNFI & & CFI & SRMR & RMSEA \\
\hline Barnardo’s & \multicolumn{2}{|c|}{164.84} & 71 & 0.92 & & 0.94 & 0.07 & 0.09 \\
\hline BBC & \multicolumn{2}{|c|}{138.96} & 71 & 0.97 & & 0.97 & 0.05 & 0.08 \\
\hline \multirow[t]{2}{*}{ Items } & \multicolumn{2}{|l|}{ Usefulness } & \multicolumn{2}{|l|}{ Efficiency } & \multicolumn{2}{|l|}{ Affect } & \multicolumn{2}{|l|}{ Dynamism } \\
\hline & Barnardo's & BBC & Barnardo's & BBC & Barnardo's & BBC & Barnardo's & BBC \\
\hline Indispensable & 0.61 & 0.52 & & & & & & \\
\hline Useful & 0.69 & 0.78 & & & & & & \\
\hline Civic-minded & 0.50 & 0.66 & & & & & & \\
\hline Efficient & & & 0.71 & 0.68 & & & & \\
\hline Serious & & & 0.64 & 0.57 & & & & \\
\hline $\begin{array}{l}\text { Well- } \\
\text { managed }\end{array}$ & & & 0.61 & 0.72 & & & & \\
\hline $\begin{array}{l}\text { Excellent } \\
\text { service }\end{array}$ & & & 0.59 & 0.71 & & & & \\
\hline $\begin{array}{l}\text { Uses assets } \\
\text { wisely }\end{array}$ & & & 0.65 & 0.81 & & & & \\
\hline Friendly & & & & & 0.76 & 0.89 & & \\
\hline Generous & & & & & 0.64 & 0.76 & & \\
\hline Warm & & & & & 0.71 & 0.78 & & \\
\hline Engaging & & & & & 0.73 & 0.83 & & \\
\hline Modern & & & & & & & 0.90 & 0.83 \\
\hline Innovative & & & & & & & 0.78 & 0.80 \\
\hline AVE & 0.37 & 0.44 & 0.43 & 0.49 & 0.51 & 0.66 & 0.71 & 0.67 \\
\hline CR & 0.632 & 0.69 & 0.79 & 0.83 & 0.80 & 0.97 & 0.83 & 0.79 \\
\hline $\begin{array}{l}\text { Cronbach's } \\
\alpha\end{array}$ & 0.626 & 0.69 & 0.79 & 0.82 & 0.80 & 0.88 & 0.82 & 0.79 \\
\hline Mean & 11.39 & 11.64 & 18.47 & 18.13 & 14.03 & 16.03 & 6.09 & 8.19 \\
\hline $\begin{array}{l}\text { Std. } \\
\text { Deviation }\end{array}$ & 1.862 & 2.12 & 3.05 & 3.59 & 2.615 & 3.11 & 1.671 & 1.68 \\
\hline
\end{tabular}

Table 4

Discriminant Validity of the Constructs

Discriminant Validity of the Constructs: Barnardo's

\begin{tabular}{lrrrr}
\hline Barnardo's & 1 & 2 & 3 & 4 \\
\hline 1. Usefulness & $\mathbf{0 . 3 7}$ & 0.49 & 0.51 & 0.18
\end{tabular}




\begin{tabular}{lllll} 
2. Efficiency & 0.70 & $\mathbf{0 . 4 3}$ & 0.54 & 0.23 \\
3. Affect & 0.72 & 0.73 & $\mathbf{0 . 5 1}$ & 0.59 \\
4. Dynamism & 0.42 & 0.48 & 0.77 & $\mathbf{0 . 7 1}$ \\
\hline
\end{tabular}

Discriminant Validity of the Constructs: BBC Children in Need

\begin{tabular}{lrrrc}
\hline BBC CN & 1 & 2 & 3 & 4 \\
\hline 1. Usefulness & $\mathbf{0 . 4 4}$ & 0.64 & 0.61 & 0.62 \\
2. Efficiency & 0.79 & $\mathbf{0 . 4 9}$ & 0.56 & 0.55 \\
3. Affect & 0.78 & 0.75 & $\mathbf{0 . 6 6}$ & 0.73 \\
4. Dynamism & 0.79 & 0.74 & 0.85 & $\mathbf{0 . 6 7}$ \\
\hline
\end{tabular}

Note: Correlations are below the diagonal, squared correlations are above the diagonal, and AVE estimates are presented on the diagonal.

Table 5

Initial Items for the Improved Nonprofit Brand Image Scale

\begin{tabular}{lllll}
\hline $\begin{array}{l}\text { Indispensable } \\
\text { Useful }\end{array}$ & Caring & Generous & Pioneering & Fair \\
Civic-Minded & Likeable & Warm & Exciting & Moral \\
Effective & & Engaging & Progressive & Righteous \\
& Well-managed & Modern & Reliable & Honorable \\
Worthwhile & Provides excellent & & & \\
Helpful & service & Innovative & Trustworthy & \\
Valuable & Uses assets wisely & Visionary & Reputable & \\
Efficient & Financially sound & Forward-thinking & Sincere & \\
Capable & Compassionate & Proactive & Responsible & \\
Serious & Favorable & Contemporary & Recognizable & \\
\hline
\end{tabular}

Table 6

Respondents’ Profile

\begin{tabular}{|c|c|c|c|c|}
\hline & \multicolumn{2}{|c|}{$n$} & \multicolumn{2}{|c|}{ Percentage \% } \\
\hline & Barnardo's & NSPCC & Barnardo's & NSPCC \\
\hline \multicolumn{5}{|l|}{ Gender } \\
\hline Male & 93 & 99 & 46.5 & 49.5 \\
\hline Female & 107 & 101 & 53.5 & 50.5 \\
\hline \multicolumn{5}{|l|}{ Age } \\
\hline 20 and under & 98 & 4 & 49 & 2 \\
\hline $21-30$ & 101 & 102 & 50.5 & 51 \\
\hline $31-40$ & - & 65 & - & 32.5 \\
\hline
\end{tabular}


$41-50$

51 and over

\section{Income}

Less than $£ 10,000$

$£ 10,000-£ 20,000$

$£ 20,000-£ 30,000$

$£ 30,000-£ 40,000$

$£ 40,000$ plus
1

- 12

$185 \quad 31$

$9 \quad 81$

$1 \quad 55$

$1 \quad 27$

4
0.5

$-$

8.5

6

15.5

40.5

27.5

13.5

3

Table 7

Statistics for 6 dimensions of nonprofit brand image

\begin{tabular}{lcccccc}
\hline Model & $\chi \mathbf{2}$ & df & NNFI & CFI & SRMR & RMSEA \\
\hline Study 2 & 200.69 & 144 & 0.99 & 0.99 & 0.04 & 0.04 \\
\hline Study 3 & 406.74 & 175 & 0.98 & 0.98 & 0.04 & 0.07 \\
\hline
\end{tabular}

Constructs used in the study and factor loadings

\begin{tabular}{|c|c|c|c|c|c|c|c|c|c|c|c|c|}
\hline \multirow[t]{2}{*}{ Items: } & \multicolumn{2}{|c|}{ Usefulness } & \multicolumn{2}{|c|}{ Efficiency } & \multicolumn{2}{|c|}{ Affect } & \multicolumn{2}{|c|}{ Dynamism } & \multicolumn{2}{|c|}{ Reliability } & \multicolumn{2}{|c|}{ Ethicality } \\
\hline & St.2 & St.3 & St.2 & St.3 & St.2 & St.3 & St.2 & St.3 & St. 2 & St.3 & St.2 & \begin{tabular}{l|l} 
St.3 \\
\end{tabular} \\
\hline Effective & 0.78 & 0.9 & & & & & & & & & & \\
\hline Worthwhile & 0.88 & 0.78 & & & & & & & & & & \\
\hline Helpful & 0.90 & 0.78 & & & & & & & & & & \\
\hline Efficient & & & 0.68 & 0.86 & & & & & & & & \\
\hline Well-managed & & & 0.74 & 0.89 & & & & & & & & \\
\hline Uses assets wisely & & & 0.79 & 0.89 & & & & & & & & \\
\hline Innovative & & & & & & & 0.75 & 0.82 & & & & \\
\hline Forward-thinking & & & & & & & 0.75 & 0.93 & & & & \\
\hline Progressive & & & & & & & 0.69 & 0.89 & & & & \\
\hline Responsible & & & & & & & & & 0.89 & 0.9 & & \\
\hline Reputable & & & & & & & & & 0.85 & 0.92 & & \\
\hline Sincere & & & & & & & & & 0.91 & 0.83 & & \\
\hline Compassionate & & & & & 0.83 & 0.93 & & & & & & \\
\hline Favorable & & & & & 0.82 & 0.94 & & & & & & \\
\hline Friendly & & & & & 0.87 & 0.8 & & & & & & \\
\hline Ethical & & & & & & & & & & & 0.87 & 0.91 \\
\hline Moral & & & & & & & & & & & 0.91 & 0.92 \\
\hline Righteous & & & & & & & & & & & 0.76 & 0.93 \\
\hline $\mathrm{M}$ & 5.3 & 4.8 & 4.7 & 5.3 & 5.3 & 5.1 & 4.2 & 4.4 & 5.3 & 4.8 & 5.4 & 5.1 \\
\hline $\mathrm{SD}$ & 1.01 & 1.06 & 0.77 & 1.16 & 0.95 & 1.2 & 0.93 & 1.07 & 1.02 & 1.11 & 1.08 & 1.24 \\
\hline Cronbach's $\alpha$ & 0.89 & 0.83 & 0.78 & 91 & 0.88 & 0.92 & 0.77 & 0.91 & 0.91 & 0.92 & 0.88 & 0.94 \\
\hline $\mathrm{CR}$ & 0.89 & 0.86 & 0.78 & 0.91 & 0.88 & 0.92 & 0.77 & 0.91 & 0.91 & 0.91 & 0.89 & 0.94 \\
\hline AVE & 0.73 & 0.68 & 0.55 & 0.88 & 0.64 & 0.7 & 0.53 & 0.77 & 0.78 & 0.78 & 0.72 & 0.84 \\
\hline
\end{tabular}

Note: Study 2 - Barnardo’s sample; Study 3 - NSPCC sample 
Table 8

Item-Total Correlations for the 6 nonprofit brand image measures

\begin{tabular}{|c|c|c|}
\hline \multirow[t]{2}{*}{ Scales } & \multicolumn{2}{|c|}{ Corrected Item-Total Correlation } \\
\hline & Barnardo’s & NSPCC \\
\hline \multicolumn{3}{|l|}{ Usefulness } \\
\hline Effective & 0.73 & 0.72 \\
\hline Worthwhile & 0.79 & 0.66 \\
\hline Helpful & 0.82 & 0.7 \\
\hline \multicolumn{3}{|l|}{ Efficiency } \\
\hline Efficient & 0.58 & 0.79 \\
\hline Well-managed & 0.61 & 0.85 \\
\hline Uses assets wisely & 0.65 & 0.83 \\
\hline \multicolumn{3}{|l|}{ Affect } \\
\hline Compassionate & 0.74 & 0.84 \\
\hline Favorable & 0.81 & 0.88 \\
\hline Friendly & 0.75 & 0.78 \\
\hline \multicolumn{3}{|l|}{ Dynamism } \\
\hline Innovative & 0.61 & .76 \\
\hline Forward-thinking & 0.64 & 0.87 \\
\hline Progressive & 0.56 & 0.83 \\
\hline \multicolumn{3}{|l|}{ Reliability } \\
\hline Responsible & 0.82 & 0.79 \\
\hline Reputable & 0.8 & 0.83 \\
\hline Sincere & 0.85 & 0.88 \\
\hline \multicolumn{3}{|l|}{ Ethicality } \\
\hline Ethical & 0.78 & 0.9 \\
\hline Moral & 0.83 & 0.84 \\
\hline Righteous & 0.71 & 0.89 \\
\hline
\end{tabular}

Table 9

Correlations and Discriminant Validity of the Constructs

Study 2: Barnardo’s

\begin{tabular}{lcccccc}
\hline & 1 & 2 & 3 & 4 & 5 & 6 \\
\hline Usefulness & $\mathbf{0 . 7 3}$ & 0.24 & 0.40 & 0.16 & 0.38 & 0.25 \\
Efficiency & 0.49 & $\mathbf{0 . 5 5}$ & 0.29 & 0.20 & 0.24 & 0.21
\end{tabular}




$\begin{array}{lllllll}\text { Affect } & 0.63 & 0.54 & \mathbf{0 . 6 4} & 0.26 & 0.41 & 0.37 \\ \text { Dynamism } & 0.40 & 0.45 & 0.51 & \mathbf{0 . 5 3} & 0.16 & 0.16 \\ \text { Reliability } & 0.62 & 0.49 & 0.64 & 0.40 & \mathbf{0 . 7 8} & 0.32 \\ \text { Ethicality } & 0.50 & 0.46 & 0.61 & 0.40 & 0.57 & \mathbf{0 . 7 2}\end{array}$

Note: Correlations are below diagonal, squared correlations are above the diagonal, and AVE estimates are presented on the diagonal

Study 3: NSPCC

\begin{tabular}{lcccccc}
\hline & 1 & 2 & 3 & 4 & 5 & 6 \\
\hline Usefulness & $\mathbf{0 . 6 8}$ & 0.52 & 0.49 & 0.37 & 0.48 & 0.48 \\
Efficiency & 0.72 & $\mathbf{0 . 7 8}$ & 0.45 & 0.29 & 0.48 & 0.50 \\
Affect & 0.70 & 0.67 & $\mathbf{0 . 8 0}$ & 0.35 & 0.50 & 0.55 \\
Dynamism & 0.61 & 0.54 & 0.59 & $\mathbf{0 . 7 7}$ & 0.23 & 0.45 \\
Reliability & 0.69 & 0.69 & 0.71 & 0.48 & $\mathbf{0 . 7 8}$ & 0.48 \\
Ethicality & 0.69 & 0.71 & 0.74 & 0.67 & 0.69 & $\mathbf{0 . 8 4}$ \\
\hline
\end{tabular}

Note: Correlations are below diagonal, squared correlations are above the diagonal, and AVE estimates are presented on the diagonal 
Table 10

Assessment of the nomological validity of scales

REGRESSION ANALYSIS RESULTS - Barnardo's sample

\begin{tabular}{l|c|c|}
\hline \multirow{2}{*}{ Parameter } & \multicolumn{2}{|c}{ Barnardo's } \\
\cline { 2 - 3 } & St. Coefficient (T-Value) \\
\cline { 2 - 3 } Usefulness & TIME & MONEY \\
\cline { 2 - 3 } Efficiency & $.29(3.08)$ & $.23(2.45)$ \\
\cline { 2 - 3 } Affect & $.32(2.65)$ & $.24(1.99)$ \\
\cline { 2 - 3 } Dynamism & $.40(4.26)$ & $.35(3.50)$ \\
\cline { 2 - 3 } Reliability & $.41(4.27)$ & $.49(5.08)$ \\
Ethicality & $.39(4.56)$ & $.34(3.83)$ \\
\cline { 2 - 3 } & $.15(1.73)$ & $.20(2.21)$ \\
\hline
\end{tabular}

$\begin{array}{lll}\mathrm{R}^{2} & .38 & .39\end{array}$

*** $\mathrm{p}<0.01,{ }^{* *} \mathrm{p}<0.05,{ }^{*} \mathrm{p}<0.10 \mathrm{a}=$ critical t-values are $1.282,1.645$ and 2.325 for $\alpha=0.10, \alpha=0.05$ and $\alpha=$ 0.01 respectively (one-tailed test as all hypotheses are one-directional)

Table 11

Assessment of the nomological validity of scales

\section{REGRESSION ANALYSIS RESULTS - NSPCC sample}

\begin{tabular}{|c|c|c|}
\hline & \multicolumn{2}{|c|}{ NSPCC } \\
\hline \multirow[t]{2}{*}{ Parameter } & \multicolumn{2}{|c|}{ St. Coefficient (T-Value) } \\
\hline & TIME & MONEY \\
\hline \multirow{6}{*}{$\begin{array}{l}\text { Usefulness } \\
\text { Efficiency } \\
\text { Affect } \\
\text { Dynamism } \\
\text { Reliability } \\
\text { Ethicality }\end{array}$} & $.59(6.93)$ & $.63(7.31)$ \\
\hline & $.47(5.86)$ & $.5(6.02)$ \\
\hline & $.46(5.85)$ & .48 (5.93) \\
\hline & .57 (6.72) & $.58(6.63)$ \\
\hline & $.52(6.34)$ & $.58(7.02)$ \\
\hline & $.43(5.8)$ & $.41(5.19)$ \\
\hline $\mathrm{R}^{2}$ & .51 & .54 \\
\hline
\end{tabular}

0.01 respectively (one-tailed test as all hypotheses are one-directional) 